ORIGINAL ARTICLE

\title{
Heart Failure in Ethiopian Children: Mirroring the Unmet Cardiac Services
}

\author{
Bezaye Nigussie ${ }^{1}$, Henok Tadele ${ }^{*}$
}

\section{OPEN ACCESS}

Citation: Bezaye Nigussie, Henok Tadele. Heart Failure in Ethiopian Children: Mirroring the Unmet Cardiac Services. Ethiop J Health Sci.2018;29 (1):811.

doi:http://dx.doi.org/10.4314/ejhs.v29i1.2

Received: July 2, 2018

Accepted:August 3, 2018

Published: January 1, 2019

Copyright: (C) 2018 Bezaye Nigussie, et al. This is an open access article distributed under the terms of the Creative Commons Attribution License, which permits unrestricted use, distribution, and reproduction in any medium, provided the original author and source are credited.

Funding:Hawassa University, Postgraduate Studies Office

Competing Interests: The authors declare that this manuscript was approved by all authors in its formand that no competing interest exists.

Affiliation and Correspondence:

${ }^{1}$ College of Medicine and Health

Sciences, Hawassa University,

Hawassa, Ethiopia

*Email: henny_2007@yahoo.com
ABSTRACT

BACKGROUND: HeartFailure (HF) is a progressive clinical and pathophysiological syndrome caused by cardiovascular and noncardiovascular abnormalities. Childhood HF has not been well studied in Sub-Sharan Africa, particularly in Ethiopia. Hence, this study aimed at describing the pattern and outcome of pediatrics $\mathrm{HF}$ at a referral-teaching hospital.

METHODS: Medical records of 216 HFchildren aged 2months to 14 years, and admitted between January 2014 and January 2016 were reviewed. Clinical information was collected, analyzed and presented in tables and pie charts.

RESULTS: A total of 2000 children were admitted to Hawassa University Hospital during the study period. HF accounted for $10.8 \%$ (216) of pediatrics admissions, $51.9 \%$ males. The median age of the study subjects was 6years. Functionally, NYHA/Ross class III and IV consisted 65(30.1\%) and 139(64.4\%) of HF. Structural heart diseasewas the commonest cause of $\mathrm{HF}$, 144(66.7\%): Rheumatic heart disease (RHD),75(52\%), and congenital heart disease (CHD),64(44.5\%). Anemia and renal cases contributed to 50(23.1) and 12(5.6\%) of HF.CHD was predominantly documented in <5years. Pneumonia 66(42.9\%), and infective endocarditis 29(18.8\%) were the common precipitating/comorbid conditions with $\mathrm{HF}$.Thecase fatality rate of $\mathrm{HF}$ was $13.9 \%$ ( 30).

CONCLUSION: In this study, HF accounted for a tenth of pediatrics admissions. Structural heart disease was the commonest cause of heart failure. CHD and RHD affected predominantly children of <5years of age and $>5$ years of age. Echocardiographic screening of $\mathrm{HF}$ cases for structural heart disease and optimal care for patients with underlying structural heart disease are recommended.

KEYWORDS: Heart failure, children, pattern,outcome,Ethiopia

\section{INTRODUCTION}

Heart Failure(HF) is a progressive clinical and pathophysiological syndrome caused by cardiovascular and noncardiovascular abnormalities (1). Childhood cardiovascular disorders including HF are associated with high morbidity and mortality especially in subSaharan Africa where palliative and definitive treatments seem far from reach (2-5).

DOI: http://dx.doi.org/10.4314/ejhs.v29i1.2 
Causes of HF are significantly different in children, and many cases are due to congenital malformations such as left-to-right shunts (6).Cardiomyopathies are common causes of HF in developed nations, though not all present with HF (7-8). The developing countries have a double burden of HF causes: congenital heart disease, myocarditis and cardiomyopathies with additional burden of rheumatic heart disease, nutritional problems and tropical diseases. Although, the exact prevalence of HF in children is not known in developing countries due to limited data (9-10). Pediatrics HF incurs a considerable treatment cost than adult population because of a longer hospital stay and increased procedure requirement. This in turn affects the structure and the economic productivity of families $(1,11)$.

Clinical features suggestive of HF in infants include tachypnea, feeding difficulty, diaphoresis, irritability with poor feeding and even refusal of feeds. Edema of face and limbs is uncommon in infants and young children. Tachycardia, tachypnea, gallop rhythm and hepatomegaly are features of $\mathrm{HF}$ in infants. Older children and adolescents presentwith fatigue, effort intolerance, dyspnea, orthopnea, abdominal pain, dependent edema and ascites. The New York Heart Association (NYHA) HF classification isnot readily applicable to younger children (12). The modified Ross classification is used for $\mathrm{HF}$ severity classification in children (13). Transthoracic echocardiography is indicated in all cases of pediatric HF to exclude possible structural disease. Chest X-ray, electrocardiography, tests for infectious or precipitating factors are also indicated $(10,12)$.

Pediatrics HF management principles are developed from a combination of clinical experience, small scale studies and extrapolation of adult studies (14). Treatment principles include treatment of the cause, correction of any precipitating event and alleviation of systemic or pulmonary congestion. Precipitating factors include infections, anemia, drug discontinuation, infective endocarditis and rheumatic recurrence (12).

The status of HF in children is not well studied in Sub-Saharan Africa with very limited reports and only a single study from Ethiopia (10,
15-16). We aimed at describing the clinical characteristics of pediatrics $\mathrm{HF}$ at a tertiary hospital in Hawassa, Southern Ethiopia. The study will provide additional knowledge to the underdocumented pediatrics HF and also serves as a resource information for future intervention.

\section{METHODS}

Study area: The study was conducted in the Department of Pediatrics and Child Health, Hawassa UniversityComprehensive Specializedhospital. The hospital is located in Hawassa City, $275 \mathrm{~km}$ south of Ethiopia's capital city-AddisAbaba. The hospital is a referral and tertiary teaching center. The department has a cardiac unit staffed with trained Pediatric echocardiographer with Echocardiography machines (2-D, M-mode and color Doppler imaging facilities), electrocardiography and radiology imaging services.

Study Design: Medical records of study subjects were retrieved from the central medical recordsarchive.Demographic,clinicalandechocardi ographicdata were collected from medical records of study subjects using questionnaires developed.

Study population: All pediatric HF cases who were admitted to Hawassa University Comprehensive Specialized Hospital (HUCSH) between January2014 and January 2016were included in the study.

Inclusion criteria: All admitted pediatrics HF cases aged 2months to 14years were included.

Exclusion criteria: Patients with incomplete medical records and patients with suspected structural heart disease with no echocardiography report were excluded from the study.

A sample size of 214 was calculated based on the assumptions of $16.7 \% \mathrm{HF}$ admissions (15), 95\% confidence interval with $5 \%$ margin of error. However all $216 \mathrm{HF}$ study subjects fulling the predefined criteria during the study period were included in the study.

Operational definitions: Heart failure was defined by simultaneous presence of 3 or all of the criteria:

1. tender hepatomegaly- with liver edge palpable $3 \mathrm{~cm}$ below the right costal margin along the midclavicular line.

DOI: http://dx.doi.org/10.4314/ejhs.v29i1.2 
2. Significant tachycardia for age (heart rate $>160 \mathrm{bpm}$ in infancy, $>140 \mathrm{bpm}$ at the age of 2 years, $>120 \mathrm{bpm}$ the age of 4 years, and $>100$ bpm above 6 years of age).

3. significant tachypnea for age (respiratory rate $>60 /$ min in newborn, 2months up to 12 months $>50 / \mathrm{min}$, 1year and above $40 / \mathrm{min}$ ).

4. cardiomegaly (cardiothoracic ratio $>60 \%$ in $<5$ year of age and $>50 \%$ in $>5$ years of age) (17).

Severity of HF was assessed by New York Heart Association (NYHA) or modified Ross classification for younger children $(13,18)$. Structural heart disease was defined as a disease of the heart that is either congenital (present from birth) oracquired (19). Diagnosis of pneumonia in HF patients was considered if fever, elevated white bloodcount for age, and chest x-ray evidence ofinfiltrates were documented (20). Severe acute malnutrition was defined by a very low weight forheight (below $-3 \mathrm{z}$ scores of the median WHO growth standards), by visible severe wasting, or by thepresence of nutritional edema (21). Anemia was defined when hemoglobin concentration was $<11 \mathrm{~g} / \mathrm{dl}$, $<11.5 \mathrm{~g} / \mathrm{dl}$, and $<12 \mathrm{~g} / \mathrm{dl}$ inunder five years, 511 years and 12-14 years of agerespectively (22). Outcome refers to the hospital discharge outcome of patients. World heart federation and other standard criteria were used fordiagnosis and classification of rheumatic heartdisease and congenital heart disease $(23,24)$.

Statistical methods: Data were double entered into excel spread sheet and transferred into SPSS software version 20for analysis. Descriptive statistics were usedto analyzevariables.

Ethics: Ethical clearance was obtained from institutional review board of College of Medicine and Health Sciences, Hawassa University. Written permission was obtained from Hawassa University comprehensive specialized hospital administration for retrieving medical records of study subjects.

\section{RESULTS}

Clinical characteristics: Atotal of 2000 children were admitted between 2 months and 14 years of age to HUCSH in the two years period (January 2014-January 2016). HF accounted for $10.8 \%(216)$ of pediatric inpatient admissions. The gender composition was comparable, 112 (51.9\%) were males with male to female ratio of $1.1: 1$. The median age of the study subjects was 6years. Children above the age of 5 years dominated the study population, 124 (57.4\%).

The most common presenting symptoms were cough, feeding interruption, body swelling and fast breathing in $60(27.8 \%), 55(25.5 \%)$, $34(15.7 \%)$ and $29(13.4 \%)$ of the cases. The majority of the patients had moderate to severe symptoms with NYHA/Ross class III and IV comprising $65(30.1 \%)$ and $139(64.4 \%)$ of HF cases (Table 1). Pneumonia and infective endocarditis were the common precipitating factors for HF in $66(42.9 \%)$ and $29(18.8 \%)$ of the study subjects.

Causes of heart failure: Structural heart disease was the commonest cause of heart failure, $144(66.7 \%)$ of HF cases. Anemia and renal causes contributed for 50(23.1) and 12(5.6\%) of HF cases. Hypertension related to acute post streptococcal glomerulonephritis was the cause for renal cases.

Rheumatic valvular heart disease (RHD) and congenital heart disease contributed to $75(52 \%)$ and $64(44.5 \%)$ of children with structural heart disease. Other causes like cardiomyopathies constituted only $5(3.5 \%)$ of HF cases (Figure 1 ). Mitral and aortic valves were severely affected by rheumatic heart disease and almost all (96.2\%) of RHD cases had moderate to severe valvular insufficiency.

Eighty three $(57.6 \%)$ of children with structural heart disease were aged 5years and above. All RHD cases were documented in children above 5years of age. CHD was documented in 41(64\%), 14(21.9\%) and 9(14\%) of HF cases among children aged between 2 months and 24 months, 24 months to five years, and above 5years of age, respectively. Ventricular septal defect was the commonest CHD, 25(39\%). Multiple CHDs comprising ASD with VSD, VSD with PDA, VSD and PS with D-TGA etc contributed to $18(28 \%)$ of CHDs. Others including tricuspid atresia accounted for $7(10.9 \%)$ of CHD (Figure 2). Anemia was the second most

DOI: http://dx.doi.org/10.4314/ejhs.v29i1.2 
common cause of heart failure, 50(24.3\%).

Hematologic malignancy, iron deficiency anemia and megaloblastic anemia contributed to $18(36 \%)$, $15(30 \%)$ and $13(26 \%)$ of anemia cases.

Table 1: Clinical characteristics of Pediatric heart failure at Hawassa University Comprehensive Specialized Hospital, January 2014- January 2016

\begin{tabular}{|c|c|c|}
\hline Variable & Frequency(n) & Percentage $(\%)$ \\
\hline \multicolumn{3}{|l|}{ Age in years $(n=216)$} \\
\hline$<2$ & 54 & 25 \\
\hline $2-5$ & 38 & 17.6 \\
\hline $5-10$ & 56 & 25.9 \\
\hline$\geq 10$ & 68 & 31.5 \\
\hline \multicolumn{3}{|l|}{$\operatorname{Sex}(n=216)$} \\
\hline Male & 112 & 51.9 \\
\hline Female & 104 & 48.1 \\
\hline \multicolumn{3}{|l|}{ Presenting Symptom $(\mathrm{n}=216)$} \\
\hline Cough & 60 & 27.8 \\
\hline Fast breathing & 29 & 13.4 \\
\hline Feeding interruption & 55 & 25.5 \\
\hline Body swelling & 34 & 15.7 \\
\hline Easy fatigability & 22 & 10.2 \\
\hline Fever & 4 & 1.9 \\
\hline Others ${ }^{*}$ & 12 & 5.5 \\
\hline \multicolumn{3}{|l|}{ Heart failure cause $(n=216)$} \\
\hline Structural heart disease & 144 & 66.7 \\
\hline Anemia & 50 & 23.1 \\
\hline Renal cause(hypertension) & 12 & 5.6 \\
\hline Corpulmonale & 5 & 2.3 \\
\hline Others $^{+}$ & 5 & 2.3 \\
\hline \multirow{2}{*}{\multicolumn{3}{|c|}{$\begin{array}{l}\text { Functional Classification } \\
\text { (NYHA/Modified Ross) }(n=216)\end{array}$}} \\
\hline & & \\
\hline Class IV & 65 & 30.1 \\
\hline Class III & 139 & 64.3 \\
\hline Class II & 12 & 5.6 \\
\hline \multicolumn{3}{|l|}{ Precipitating factor/comorbidity $(\mathrm{n}=154)$} \\
\hline Pneumonia & 66 & 42.9 \\
\hline Infective endocarditis & 29 & 18.8 \\
\hline Severe acute malnutrition & 10 & 6.5 \\
\hline Down syndrome & 19 & 12.3 \\
\hline Others $^{++}$ & 30 & 19.4 \\
\hline \multicolumn{3}{|l|}{ Outcome $(n=216)$} \\
\hline Improved & 178 & 82.4 \\
\hline Self-discharged against medical & 8 & 3.7 \\
\hline \multicolumn{3}{|l|}{ advice } \\
\hline Died & 30 & 13.9 \\
\hline
\end{tabular}

DOI: http://dx.doi.org/10.4314/ejhs.v29i1.2 


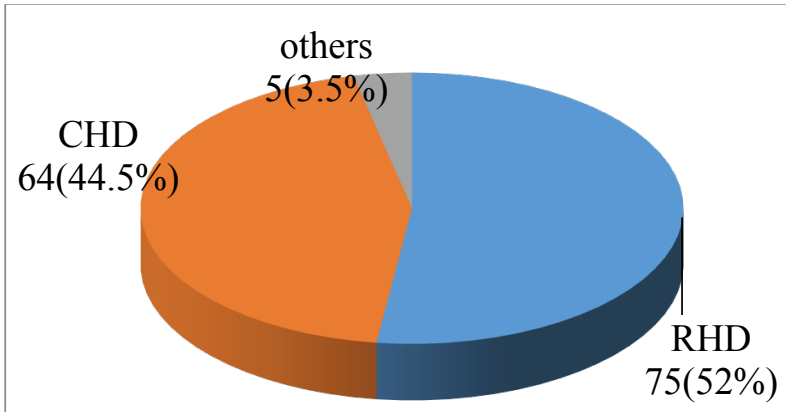

Figure 1: Pattern of structural heart disease in childhood heart failure at Hawassa University Comprehensive specialized hospital, January 2014- Janurary2016.

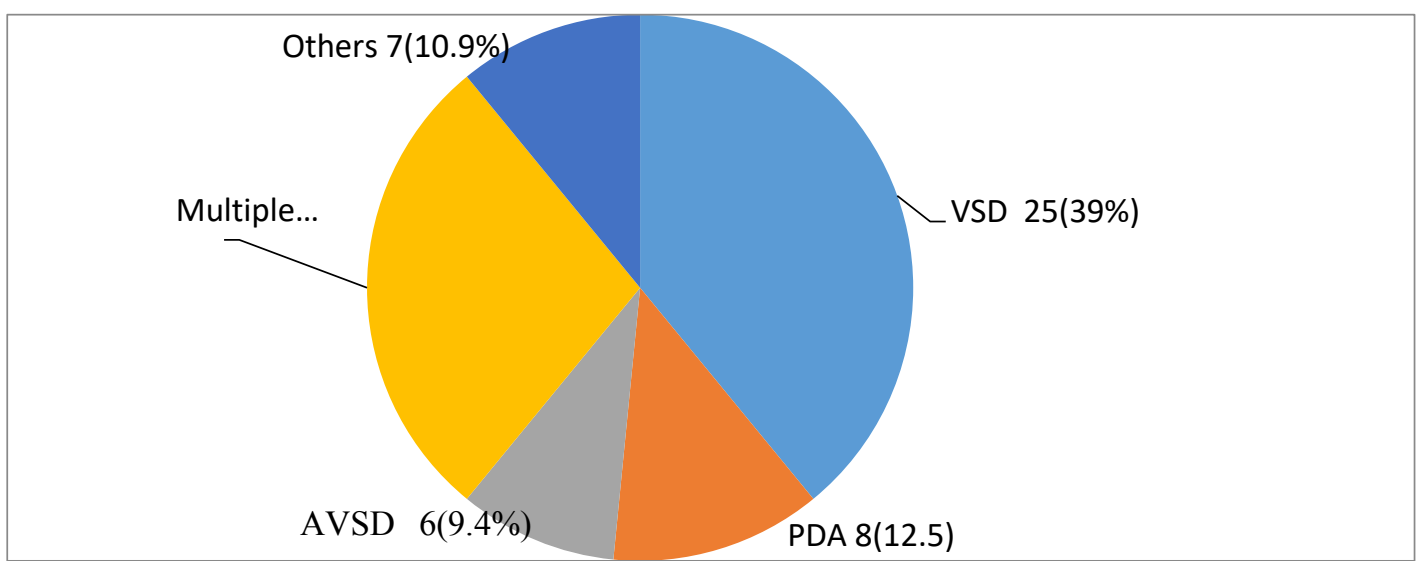

Figure 2:Pattern of congenital heart disease among children with heart failure at Hawassa University Comprehensive Specialized Hospital, January 2014- January 2016

Treatment and Outcome: Various combinations of diuretics, angiotensin converting enzyme inhibitors, $\beta$-blockers and digoxin were used to treat HF. Outof $216 \mathrm{HF}$ cases, 30 died making a case fatality rate of $13.9 \%$. One hundred seventy eight $(82.4 \%)$ were discharged improved, and $8(3.7 \%)$ left the hospital against medical advice. Twenty eight $(93.3 \%)$ of deaths were documented among patients with structural heart disease. CHD and RHD accounted for 14 deaths each.

\section{DISCUSSION}

Heart failure accounted for $10.8 \%$ (95\% CI 9.5, 12.2) of pediatric admissions in this study. This is higher than reports from the United Kingdom and Ireland, Nigeria, Kenya and Ethiopia $(7,10,17)$. However, it islower than a study conducted in Nigeria (15). It is comparable to a Belgian study $(10.4 \%)(25)$. Differences could be attributed to the difference in the age of inclusionand the capacityof the hospitals. A report from the United
Kingdom and Ireland was collected from multiple cardiac centers on a prospective basis and that might have contributed to the noted difference.

In this study, the majority of HF patients are aged 5 years and above with comparable gender composition. Age distribution is in agreement with Ethiopian study but our study subjects are older than Kenyan and Nigerian report $(10,15,16)$. The reason for older age could be the high occurrence of rheumatic heart disease above 5 years of age in our study and the high RHD burden in Ethiopia (26). Additionally,diagnosis of HF in young children could be difficult owing to the similarity of HF symptoms to pneumonia, reactive airway disease and viral respiratory infections and these resulting in misclassification of final patients' diagnosis. In underprivileged setting like ours young children with severe congenital heart disease could also dieof the underlying disease early $(12,13)$.

DOI: http://dx.doi.org/10.4314/ejhs.v29i1.2 
In our study, the majority of patients were in NYHA/Ross class III and IV. This is similar to studies conducted in Ethiopia, Kenya and Belgium. In a Nigerian study, class I and II NYHA dominate $(10,15,16,25)$. The difference could be attributed to the high occurrence of structural heart disease in our case which depletes the reserve of the heart for acute crisis state and HF in Nigerian report followed infectious diseases in normally structured heart $(27,28)$.

Pneumonia was the commonest comorbid or precipitating condition for HF in our study.

This is in agreement with other studies in children with structural heart disease $(16,17,29,30)$. The increased pulmonary circulation in HF was ascribed as a cause for pneumonia $(29,31)$. IE was also a common precipitator for HF in our study. This is similar to reports from Kenya and Ethiopia (32,33). Infective endocarditis complicates patients with structural heart disease and commonly results in heart failure.

Regarding causes of HF, structural heart disease was documented as the commonest cause in our study. This is in agreement with another study from Ethiopia (16). This is opposed to the other Sub-Saharan studies where infectious causes dominated $(10,17,29,34)$. Studies from developed nations have documented congenital heart disease and cardiomyopathies as common cause for $\mathrm{HF}$ $(7,25)$. Significant reduction of infectious diseases, community addressed primary health education, early diagnosis and treatment of common childhood infectious diseases at primary health care unitby health extension workers in Ethiopia could explain the absence of infectious etiologies as a causeof HF in our study (35-38). The difference could also be attributed to differences in level of diagnosis, care and treatment for congenital heart disease where CHD cases are underestimated in Africa owing to poor outcome (39). Childhood HF could also mirror the high burden of rheumatic heart disease in Ethiopia(26). The estimated CHD or cardiovascular congenital defects prevalence in Ethiopia is 7.9/1000 live births (40). Our finding calls for more robust community based studies to document the true burden of CHD and HF. The types of CHD in our study are similar to reports from other studies $(16,17,29)$.
Anemia was the second common cause of HF in our study, and this is in agreement with findings from Nigeria and Kenya $(10,15,17)$. This goes in line with the high prevalence of childhood anemia in Ethiopia, and also with the reported nutritional anemias occurrence mong patients with structural heart disease $(41,42)$. Our finding of renal causes is comparable to report from Nigeria (17). Untreated hypertension following acute glomerulonephritis is reported to result in HF.

In this study, the case fatality rate was $13.9 \%$. It is lower than reports from Nigeria and Ethiopia $(15,16)$, but higher than a report from Kenya (10). Higher fatality rates from Nigeria might be related to infectious diseases and its prognosis. The high occurrence of severe acute malnutrition in a study conducted at Addis Ababa could also explain the noted high mortality. A lower case fatality identified in Kenya could be attributed to the availability of better care and surgical intervention for children with structural heart disease in their setting.

Our study has several limitations. It is a single center and hospital based study. It is likely that only patients with moderate and severe symptoms presented to our hospital, and this might not reflect the full context of the disease in the community/nation. Moreover, our study is retrospective, and many important variables were missing thus making the detailed analysis of determinant variables difficult. Nevertheless, this study provides the deviating pattern of pediatrics heart failure in Ethiopia from that of sub-Saharan African countries with structural heart disease being the commonest cause. It also calls for more large scalemulticenter studies to document the real burden of pediatrics heart failure and gives insight into the needed future intervention. In this study, heart failure accounted for a tenth of pediatrics admissions. Structural heart disease was the commonest cause of heart failure. CHD and RHD affected predominantly children ofless than 5 years of age and those above 5 years of age. Echocardiographic based screening of HF patients for structural heart disease and targeted treatment ofHF cases with underlying structural heart disease are recommended.

\section{ACKNOWLEDGEMENTS}

DOI: http://dx.doi.org/10.4314/ejhs.v29i1.2 
We would like to thank the school of graduate studies of Hawassa University for financial support. We would also like to thank the College of Medicine and Health sciences administration for facilitation of the study.

\section{REFERENCES}

1. Hsu DT, Pearson GD. Heart failure in children part I: history, etiology, and pathophysiology. Circ Heart Fail 2009;2(1): 63-70.

2. Kassebaum N, Kyu HH, Zoeckler L, Olsen HE, Katie Thomas K, Pinho $\mathrm{C}$ et al.Child and Adolescent Health From 1990 to 2015 Findings From the Global Burden of Diseases, Injuries, and Risk Factors 2015 Study The Global Burden of Disease Child and Adolescent Health Collaboration. JAMA Pediatr. 2017; 171(6):57392.

3. GBD 2015 Disease and Injury Incidence and Prevalence Collaborators. Global, regional, and

4. national incidence, prevalence, and years lived with disability for 310 diseases and injuries, 19902015: a systematic analysis for the Global

5. Burden of Disease Study 2015. Lancet. 2016;388(10053):1545-1602.

6. JIeH. The global burden of congenital heart disease. Cardiovasc J Afr. 2013; 24 (4):141-5.

7. Hewitson J, Zill P. Children's heart disease in subSaharan Africa: Challenging the burden of disease. SA Heart Journal2010; 7:18-29.

8. World health organization. The selection and use of essential medicines: report of the WHO Expert Committee, March 2009 (including the 16th WHO model list of essential medicines and the 2nd WHO model list of essential medicines for children). Switzerland:WHO technical report series; 2009.

9. Andrews RE, Fenton MJ,Ridout DA, Burch M. New-onset heart failure due to heart muscle disease in childhood: a prospective study in the United kingdom and Ireland.Circulation 2008;117(1):79-84.

10. Lipshultz SE, Sleeper LA,Towbin JA, Lowe AM, Orav EJ, Cox GF et al. The incidence of pediatric cardiomyopathy in two regions of the United States. N Engl J Med. 2003;348(17):1647-55

11. Ramakrishnan S.Pediatric Heart Failure in the Developing World. Rev Recent Clin Trials. 2014;9(2):86-90.

12. Ogeng'o J, Gatonga PM, Olabu BO, Nyamweya DK, Ong'era D. Pattern of congestive heartfailure in a kenyan paediatric population. Cardiovasc $J$ Afr. 2013; 24(4):117-120.
13. Webster G,Zhang J,RosenthalD. Comparison of the epidemiology and co-morbidities of heart failure in the pediatric and adult populations: a retrospective, cross-sectional study. $B M C$ Cardiovasc Disord. 2006; 6: 23.

14. Jayaprasad N. Heart Failure in Children. Heart Views. 2016; 17(3): 92-99.

15. Ross RD,Bollinger RO,Pinsky WW.Grading the severity of congestive heart failure in infants.Pediatr Cradiol. 1992;13(2):72-5.

16. Kay JD, Colan SD, Graham TP Jr.Congestive heart failure in pediatric patients. Am Heart J. 2001;142(5):923-8

17. DuruCO,Mesiobi-AneneN, AkinbamiFO.Pediatric heart failure among emergency room admissions in a Tertiary Health Centre in Southern Nigeria. Nig J Cardiol. 2016;13:62-6.

18. Gebremariam S, Moges T. Pediatric Heart Failure, Lagging, and Sagging of Care in Low Income Settings: A Hospital Based Review of Cases in Ethiopia. Cardiol Res Pract. 2016;2016:7147234.

19. Lagunju IA, Omokhodion SI.Childhood heart failure in Ibadan.WestAfr J Med. 2003;22(1):42-5.

20. MartinDolgin;New York Association. Nomenclature and criteria for diagnosis of diseases of the heart and great vessels. $9^{\text {th }} \mathrm{ed}$. Boston:Little,Brown; 1994.

21. Daniel H. Steinberg, Stephan Staubach, Jennifer Franke, Horst Sievert. Defining structural heart disease in the adult patient: current scope, inherent challenges and future directions. European Heart Journal Supplements (2010) 12

22. $\mathrm{Hu} \mathrm{D}$, Liu Y, Tao H, Gao J.Clinical value of plasma B-type natriuretic peptide assay in pediatric pneumonia accompanied by heart failure.ExpTher Med. 2015 ;10(6):21752179.

23. World health organization, United Nations Children's Fund. WHO child growth standards and the identification of severe acute malnutrition in infants and children. switzerland: A Joint Statement by the World Health Organization and the United Nations Children's Fund; 2009

24. World Health Organization. Hemoglobin concentrations for the diagnosis of anemia and assessment of severity. Vitamin and Mineral Nutrition Information System. Geneva, World

25. Health Organization, 2011 (WHO/NMH/NHD/MNM/11.1)

(http://www.who.int/vmnis/indicators/haemoglobi n. pdf, accessed on July 31, 2018).

DOI: http://dx.doi.org/10.4314/ejhs.v29i1.2 
26. Reményi B, Wilson N, Steer A, Ferreira B, Kado $\mathrm{J}$, Kumar Ket al. World Heart Federation criteria for echocardiographic diagnosis of rheumatic heart disease--an evidence-based guideline.Nat Rev Cardiol. 2012;9(5):297-309

27. Lai WW, Mertens LL, Cohen MS, Geva T. Echocardiography Pediatric and congenital heart disease: from fetus to adult. $2^{\text {nd }} e d$.WileyBlackwell; 2016.

28. Massin MM, Astadicko I, Dessy H. Epidemiology of heart failure in a tertiary pediatric center.ClinCardiol. 2008;31(8):

388-91.

29. Dejuma Y, Abraha H, Abraham $\mathrm{H}$ et al. Prevalence of rheumatic heart disease among school children in Ethiopia: A multisite echocardiography -based screening. Int $J$ Cardiol. 2016;221:260-3.

30. Vanderlaan RD, Caldarone CA, Backx PH. Heart failure in congenital heart disease: the role of genes and hemodynamics. Pflugers Arch. 2014;466(6):1025-35.

31. Knudson JD, Cabrera. AG. The Pathophysiology of Heart Failure in Children: The Basics. CurrCardiol Rev. 2016;12(2):99-103.

32. WE Sadoh and WO Osarogiagbon. Underlying congenital heart disease in Nigerian children with pneumonia. Afr Health Sci. 2013; 13(3): 607-612.

33. Andres S, Bauer G, Rodríguez S, Novali L, Micheli D, Fariña D. Hospitalization due to respiratory syncytial virus infection in patients under 2 years of age with hemodynamically significant congenital heart disease. $J$ Pediatr (Rio J). 2012;88(3):246-52.

34. Owayed AF, Campbell DM,Wang EE.Underlying causes of recurrent Pneumonia in children.ArchPediatrAdolesc Med. 2000;154(2):190-4.

35. Moges T, Gedlu E, Isaakidis P, Kumar A et al.Infective endocarditis in Ethiopian children: a hospital based review of cases in Addis Ababa. PanAfr Med J. 2015;20:75

36. Oyungu E, NabakweE, EsamaiF. Factors that precipitate heart failure among children with rheumatic heart disease. East Afr Med $J$ 2011;88(11):384-387.

37. Omokhodion SI, LagunjuIA. Prognostic indices in childhood heart failure. WestAfr $J$ Med. 2005;24(4):325-8.

38. The Federal Democratic Republic of Ethiopia Ministry of Health.HSTP: Health Sector Transformation Plan: 2015/16 - 2019/20 (20082012 EFY). Addis Ababa: Federal Democratic Republic of Ethiopia Ministry of Health; 2015

39. Abrahim O, Linnander E, Mohammed H, Fetene N, Bradley E. A Patient-Centered Understanding of the Referral System in Ethiopian Primary Health Care Units. PLoS ONE 2015;10(10)

40. Fetene N, Linnander E, Fekadu B, Alemu H, Omer $\mathrm{H}$, Canavan $M$ et al.The Ethiopian Health Extension Program and Variation in Health Systems Performance: What Matters? PLoS One. 2016;11(5).

41. Misganaw A, Haregu TN, Deribe K, Tessema GA, Deribew A, Melaku YA et al. National mortality burden due to communicable, non-communicable, and other diseases in Ethiopia, 1990-2015: findings from the Global Burden of Disease Study 2015. Population Health Metrics2017;15:29.

42. Zühlke L, Mirabel M, MarijonE.Congenital heart disease and rheumatic heart disease in Africa: recent advances and current priorities. Heart.2013;99(21):1554-1561.

43. Christianson A., Howson CP, Modell B. March of Dimes. Global report on birth defects. The hidden toll of dying and disabled children. New York: March of dimes birth defects foundation; 2006.

44. Shah R, AgarwalAK.Anemia associated with chronic heart failure: current concepts.ClinInterv Aging. 2013; 8: 111-122.

45. Melku M, Takele WW, Anlay DZ, Ekubagewargies DT, Getaneh Z, Abebe M, Abebe Z. Male and undernourished children were at high risk of anemia in Ethiopia: a systematic review and meta-analysis. Ital J Pediatr. 2018;44(1):79. 